\title{
Medical ethics and the clinical curriculum: a case study
}

\author{
Len Doyal with Brian Hurwitz and John S Yudkin, Middlesex Polytechnic, General Practitioner and \\ Whittington Hospital respectively
}

\section{Authors' abstract}

There are very few medical ethics courses in British medical schools which are a formal part of the clinical curriculum. Such a programme is described in the following, along with the way in which the long-term curriculum committee of the University College and Middlesex Hospital Foint Medical School was persuaded to make it compulsory for first-year students. Pedagogical lessons which have been learned in its planning and implementation are outlined and teaching materials are included concerning student and course assessment which should be useful for others engaged in similar work. Finally, some of the institutional obstacles facing such attempts are discussed, particularly problems concerning timetabling, different types of opposition and the consequent importance of building alliances among clinical teaching staff.

\section{Introduction}

In September 1985, Brian Hurwitz and I began to teach medical ethics to first-year clinical students of the newly formed Joint University College and Middlesex Hospital Medical School. The course consists of 12 sessions covering the major topics in the field and is taught three times a year at the Whittington Hospital, where one third of the first-year students are based each term in groups of around 70 . Because of its length, structure and the fact that after a trial period it was approved as a formal and assessed part of the clinical curriculum, the course may be unique in the UK. It has met with great success with students and some staff and led, among other things, to a King's Fund Fellowship at the Centre of Medical Law and Ethics at King's College, London. In the following paper, we will describe the background to the development of the course, its current content and method of presentation, the approach which we have taken to its assessment, details of the student response to it, and some of the problems encountered in trying to make it a success. In doing so, we shall focus on experiences which have

\section{Key words}

Teaching medical ethics. particular relevance to those who are attempting to get similar programmes off the ground, often no doubt in the face of considerable opposition.

\section{Background}

In 1982/3, we began a series of informal and optional seminars on a weekly basis on social issues within modern medicine. The topics we chose were wideranging and covered everything from debates concerning prevention $\mathrm{v}$ cure to health and safety at work. Initially, medical ethics constituted only a small part of the programme. The innovative character of these sessions concerned not so much the originality of the topics chosen - these were fairly standard fare for any short course in social medicine. Rather it was the format of presentation that proved particularly successful in stimulating discussion and interest. Each session consisted of a brief introduction to the issue for that week (for example why so many people smoke) followed by a video - usually from a relevant television programme - highlighting the concepts and arguments raised. A discussion then ensued which was designed to elicit responses from as many of those present as possible and to encourage debate between them. The results were often quite electric - excellent interchange with maximum participation.

Yet there were problems and serious ones. The only slot that we could find on the timetable when a significant number of students were even potentially free was on one afternoon at 4:30 pm. This meant that audiences were small and inevitably self-selected with all of the dangers of insularity that this can bring. Further, it became clear that some topics were being discussed at too general a level for many of the students, who were more at home with traditional case presentation. In reviewing what might be done about this, three things became clear. First, it was by that stage obvious that the most popular topics concerned ethical issues of one sort or another. For example, the week devoted to the abortion debate always attracted maximum attendance. For this reason and spurred on by the General Medical Council (GMC) ruling concerning ethics teaching in medical schools, we decided to devote the entire programme to moral issues, including some which are unorthodox by 
conventional standards (for example the ethical dilemmas facing doctors in underdeveloped countries). Second, we had to find another time when most students would be available and to ensure that they would all be maximally motivated to attend. And third, we were convinced that we should retain the format of a short introductory lecture, video and discussion, but with the video being devoted to cases posing specific moral dilemmas.

\section{Medicine and morality: a course in medical ethics}

These changes proved remarkably successful. With the help and encouragement of Mr John Cochrane, the Undergraduate Sub-Dean at the Whittington, and $\mathrm{Dr}$ John S Yudkin, Consultant and Senior Lecturer, we discovered a time on Tuesdays when most students were free: 12:30-2:00 pm. Both encouraged us to run our newly formulated ethics course as a trial for one term and if successful to propose it as a formal part of the first-year clinical programme. Dr Yudkin has participated fully in its planning and operation. Retaining the format of the earlier course (lecture/ video/discussion), its general content was and still is as follows:

\section{Syllabus}

1. Moral reasoning and medical ethics: Rules in everyday life. Moral rules: an introduction. Moral rules and medical practice: protect life/health, respect autonomy. The philosophical character of moral rules and why they do not dictate their own interpretation. Disputes about interpretation and their resolution. Persons v bodies. Video: a case concerning euthanasia. 2. The rights and duties of doctors: More on protecting life and respecting autonomy in practice. The concepts of 'rights' and 'duties'. Moral foundations of the obligations of doctors. Universal moral values $\mathrm{v}$ contract. Clashes between professional and private moral commitments. Telling the truth as an example. How much truth are doctors obligated to tell? Video: a case concerning terminal care.

3. Medicine, autonomy and confidentiality: Why is confidentiality so important for the practice of medicine? The philosophical character of promises. Under what circumstances - if any - can breaking a confidence be justified? Obligations to patients $v$ obligations to the public. Conflicts of interest and why general practitioners have such a tough time of it. Video: a case concerning venereal disease.

4. Morality and scarce resources: Choosing who gets what in the face of scarcity. The concept of 'entitlement'. Two rival approaches to moral justification: utilitarianism v deontology. Sexism, ageism and scarce resources. The importance of collective decisionmaking. Can politics be kept out of medicine? Video: a case concerning kidney machines.

5. The ethics of medical experimentation: Can the selective treatment of patients for research purposes be morally justified? What about other forms of voluntary participation in potentially hazardous experiments? Individual autonomy and the problems of informed consent. The rights of patients and the problem of expertise. The rights of doctors and the importance of medical research. The constitution of research ethics committees. Video: a case concerning cancer research with geriatric patients.

6. And what is life?: Back to persons. Biological $v$ theological and social definitions of personhood. The philosophical importance of language use in this respect. The concept of biological 'viability' and its dependence on the state of technological advance. The morality of embryo experimentation and what to do with the spare embryos. Evaluating the Warnock Report. The importance of public opinion in resolving moral disputes in medicine. Video: a case concerning infertility.

7. A woman's right to choose: The question of abortion. Utilitarian and deontological arguments both pro and con. The law. Further problems about defining life and autonomy in relation to the importance of protecting and respecting them (for example the perils of the 'potentiality' argument). Illustrations of the use of counterexample in moral argument through taking arguments both pro and con to extreme limits. Video: a case concerning abortion. The ethical dilemmas of surrogacy. More on Warnock 8. Morality and paediatrics: Giving birth to and caring for disadvantaged children - who decides? Y more on personhood. What constitutes a 'severe handicap. The social character of criteria of normality. Why plausible individual cases of omission or commission leading to death can have problematic moral and legal implications. The Arthur case and the case of Baby Doe. Determining the rights and duties of doctors $\mathrm{v}$ the rights and duties of parents. Video: a case concerning neonatal brain damage.

9. Morality and mental illness: Defining mental disturbance and related debates. Does the lack of a specific aetiology for mental disturbance lead to ethical problems for orthodox psychiatric medicine. More on the social character of normality and the difficulties of psychiatric diagnosis. The problem of determining the rights and duties of those who suffer from impaired autonomy. The justifiability of behaviour therapy, force and drugs as treatments. Video: a case concerning anorexia.

10. The ethics of prevention $v$ cure: The environmental context of protecting life. Questioning the importance of curative medicine in explaining the $\omega$ decline of the infectious diseases. Back to the politics of resource allocation. If doctors are morally obligated to protect life and health collectively as well as individually, should a larger percentage of the health budget and the medical curriculum be devoted to social medicine and primary care? To what extent should individuals be held morally responsible for illnesses which they could themselves have prevented and to what extent should they be given treatment? Video: 
a case concerning smoking.

11. Medicine, morality and underdevelopment: More on prevention $\mathrm{v}$ cure. Ethics, political economy and patterns of illness in the Third World. Who can be said to be morally responsible for such high levels of mortality and morbidity? To what extent can good health be regarded as a universalisable right? Hard choices: medical resource allocation against the background of severe resource constraints. Why primary care is an ethical as well as medical issue. Implications for medical education in underdeveloped countries. Video: the case of Zimbabwe.

12. Medical ethics and medical education: Learning to be a moral doctor $\mathrm{v}$ getting doctored. The moral trials and tribulations of being a medical student. Relationships between students and teachers. The ethics of educational authority. Relationships between students and patients. Encountering moral dilemmas for the first time and against the background of limited formal responsibility. Relationships between students and students. The ethics of professional and educational competition. The ethics of the curriculum. Back to prevention $v$ cure. Video: the case of a London medical school.

With the exception of the last, each of the preceding sessions conforms to the mode of presentation already outlined. We believe that a brief introductory lecture is necessary to outline the philosophical background for medical students to get the most benefit from the video and the discussion which follows. Without such an overview, only the very best students will feel that they have a sufficient conceptual 'take' on the case material to say something confidently about it. Suffice it to say that the specific case presented in each session inevitably suggests many others which are mentioned by them, or us, and which together usually cover the spectrum of arguments which need to be engaged. Further, students are always encouraged at the beginning of each session to try to integrate into the discussion any relevant clinical material which they have experienced or heard about on the wards. Finally, a minimal amount of reading from the established texts is assigned for each session with multiple copies available in the library.

\section{Assessing them and us}

We realised from the beginning that if we were to get the students to take the course and the medical school to take us seriously then both they and we would have to be assessed. For the student evaluation of the course and our performance, we distributed - and continue to do so - the following questionnaire at the end of each programme:

\section{Student Evaluation: 'Medicine and morality' Please answer all of the following:}

1. Approximately how many of the ethics sessions have you attended?
2. How interesting did you find the sessions as a whole? (For all questions of this type we structured the answers as ... Very; . . Fairly; ... Not Very; ... . Not At All)

3. Which were the most interesting sessions which you attended?

4. How relevant to medical education did you consider the specific issues comprising the programme?

5 . Were there any issues which you think should have been included but were not?

6 . Given the small amount of time allocated to the course, its presentation was an attempt to combine both a formal lecture component and a more informal discussion component. How successful would you rate this attempt?

7. Do you have any other remarks about the presentation of the course and/or its balance?

8. We also tried to integrate a film component into the course. How would you rate its success?

9. In your syllabus, a small amount of reading was recommended. How much did you do? (. . . All; ... Some; . . . None)

10. Would you like to see further courses on medical ethics in your second and third years?

11. Provided that you were convinced that it could be done objectively, would you be for or against medical ethics becoming a formally assessed subject counting towards your overall result?

12. What were the main factors which prevented you from attending sessions?

After one trial-term the resulting feedback was gratifyingly positive. Attendance was high (between one half and two thirds on a regular basis) and it was clear that most of the students enjoyed the course, felt that it achieved a good balance and thought that it should be continued - indeed expanded! Aside from the intrinsic merits of the programme, it was on this basis that the curriculum committee agreed that the course should become a formal part of the first-year curriculum. Attendance and student evaluations have continued to be good during subsequent terms.

Yet it was also obvious that we had to evaluate the students. Here the aim was to devise a diagnostic assessment which would give us and them some idea of how much of the course they had understood. In order to convince the medical school that this was possible, especially against the background of arguments to the effect that moral understanding could not be evaluated 'objectively', we also created a trial assessment for the first group to do the course and a specimen answer paper which could in principle be used by any assessor. These are outlined below and helped to convince the curriculum committee to agree to similar assessments being incorporated into the course on a compulsory basis.

\section{Student assessment: 'Medicine and morality'}

Below you will find two fictitious cases (only one will be described here) adopted from real events which 
raise a number of issues which we considered on the course. Please read each of them and choose which one you find the most interesting. Then answer all of the questions that follow in not more than one paragraph each. In your responses, be sure to argue to give reasons for what you say - and not just to assert. Case 1: 'John K, a 32-year-old lawyer, worried for several years about developing Huntington's chorea, a neurological disorder that appears in a person's thirties or forties, bringing rapid uncontrollable twitching and contractions and progressive, irreversible dementia, leading to death in approximately ten years. John K's mother died from this disease, which is autosomal dominant and afflicts 50 per cent of an affected parent's offspring. Often parents have children before they are aware that one of them has the disease. John $\mathrm{K}$ and his wife have a child because of contraceptive failure and an unwillingness to have an abortion because of his wife's religious convictions.

John $\mathrm{K}$ has indicated to many people that he would prefer to die rather than live and die as his mother lived and died. He is anxious, drinks heavily and has intermittent depression, for which he sees a psychiatrist. Nevertheless, he is a productive lawyer.

John $\mathrm{K}$ first noticed facial twitching three months ago, and two neurologists independently confirmed a diagnosis of Huntington's. He explained his situation to his psychiatrist and requested help in committing suicide. When the psychiatrist refused, John reassured him that he did not plan to attempt suicide any time soon.

But when he went home, he ingested all his antidepressant medication, after pinning a note to his shirt to explain his actions and to refuse any medical assistance that might be offered. His wife, whom he had not told about the diagnosis, found him unconscious and rushed him to hospital without removing the note'(1).

1. Employing a fictitious example other than the above, illustrate the two most important principles guiding ethical judgements in medicine - protect life/ health and respect personal autonomy - and the tensions which exist between them.

2. Discuss how these same principles and tensions are illustrated by your chosen example.

3. Assume that in Case 1 , John $\mathrm{K}$ was successfully treated with a stomach pump by the physician in authority after reading and understanding the note. Now outline at least two ethical arguments for the course of action which was followed.

4. Outline at least two ethical arguments against this course of action.

5. Is there anything which you should never do in arriving at a medical ethical judgement about a particular patient? Why?

6. Assume that you are a member of a hospital clinical ethics committee - assuming that such things existed in Britain - which considers cases and issues like the above. Who should be represented on this committee and why? What should its powers be and why?

There is not sufficient space to repeat the whole of ? the specimen answer which convinced the sceptics that $\overrightarrow{\vec{F}}$ objective assessment of answers to the above was? feasible. Readers will be familiar with the sorts of replies which would be appropriate for the questions $\frac{\bar{m}}{\mathrm{~N}}$ asked. However, it might be of interest to include our $\vec{\nabla}$ sample answer to question 5 because of its speculative $\Omega$ character and since it gives a sense of the moral values $\%$ about which a consensus often emerges by the end of $\vec{\circ}$ each course.

5. 'There are three things which should not be done. First, doctors should not knowingly break the law. Second, they should not make ethical decisions purely $\vec{\omega}$ on the basis of an individual evaluation without, where $\dot{\omega}$ possible, consulting relevant colleagues. And third, $\vec{A}$

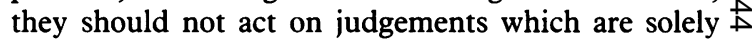
derived from religious or moral dogma. Again, they 옥 should consult with colleagues who are known to have other views, should inform patients of their ethical $\$$ convictions and offer an alternative consultation if it $\bar{D}$ is desired. The reasons for all three guidelines are $\frac{D}{3}$ similar. We have seen on the course that rules do not $\mathbb{D}_{\mathbb{D}}$ in themselves determine their varying individual interpretations and therefore cannot in themselves be referred to for guidance. One needs others for the sog. of collective instruction which is enshrined in law and in the judgements of colleagues'.

This is precisely the sort of answer that many of the students regularly reproduce. Indeed, the work produced by a large percentage of those who attempt the assessment - creative and rigorous argument of a high standard - has been gratifying.

\section{Problems}

Since its inception, the difficulties which we have confronted with the course have fallen into three 3 categories: institutional, attitudinal and logistic. Beginning with the latter, it is notoriously difficult to find a time during the week when all clinical students are free. At the Whittington, we were lucky, although we also suspect that the legendary inflexibility of the $\frac{}{0}$ clinical timetable has more to do with institutional inertia than reality. For example, many students o complain bitterly about the amount of time which they $N$ spend on their firms 'standing around and waiting for $N$ something to happen'. No doubt it can be argued that $\omega$ this experience is part of the apprenticeship character of medical education. Students have to learn that being 'on call' requires patience as well as expertise. Equally without question is the fact that a schedule based on ? ward work within firms makes finding a time when students can be sure to be exempt from medical duties $\underset{\mathbb{D}}{\mathbb{D}}$ extremely problematic. For example, they can hardly $\stackrel{?}{\mathbb{P}}$ down tools in the middle of assisting in surgery to $\varrho$ dash to their medical ethics class! However, the 
comeback surely is that if medical ethics really is believed to be an integral part of clinical medicine - if it is accepted that the practice of medicine inevitably has a moral dimension to it which students should also be trained to understand - then the small amount of time required for a proper course in the area can surely be found for most students most of the time. Timetabling difficulties do pose administrative problems which can be daunting in their complexity. However, in our experience of other types of educational institutions, these are usually solvable provided that there is not some other reason for not trying. Which brings us to attitudes.

Even though many of the students were willing to miss or curtail their lunch break to attend the course, their questionnaires revealed that some of their consultants actively discouraged them from doing so. They did this without discussion with us and after having been reminded by the Sub-Dean that the course was a formal part of their students' clinical training. Since no further action has been taken to correct this situation, many students who want to participate cannot - at least on a regular basis. In order to try to correct this, we have invited staff to the sessions but with only limited success. Interestingly, those doctors who have attended or who have been willing to discuss the course with us have almost always had their doubts allayed. In short, there can be no doubt that many doctors are distressed by the idea of ethics being 'taught' rather than 'observed in practice' on the wards. The paradox is that until they experience such teaching, along with its practical relevance to their own work, it is extremely difficult to win them over. With this in mind, we have contributed to some of the mainstream clinical teaching through discussing ethical dilemmas raised by cases presented at sessions of both the staff round and junior 'circus'. But we believe that one of our chief failings at the Whittington has been not spending enough time in discussing these issues with clinical colleagues. We hope to remedy this in the future. A further problem with attitudes concerns the course assessment. As it stands it is 'compulsory' in the sense that anyone who does not do it has this fact entered into their record. However, since most of the students know that the attitude of some of the authorities of the medical school towards the course is at best ambiguous, this is hardly a cause to take the assessment as seriously as they might despite the praise with which they otherwise speak of the course. The same problem leads to even the best students doing very little of the assigned reading. In order to correct this situation, we see no alternative but to assess ethics in the same way as other clinical subjects, with grades which count towards students' final results.

Finally, despite the endorsement of the course by the curriculum committee of the Joint School, the institutional status of the course remains both unclear and insecure, both from the perspective of long-term funding and as regards the clear support of the respective deans and others. The reasons for this are obscure, although they will no doubt be clarified in a committee which has been constituted to discuss the overall teaching of ethics in both the pre-clinical and clinical years. Such confusion is particularly surprising in the light of the popularity of the course and the interest which it has generated in other medical schools and in the profession generally. We suspect that the reasons may be specific to the internal politics of the formation of the Joint School which appear to be highly complex and to the fact that we actually teach the course at neither of the constituent medical schools. Of course, they are also in part due to some of the attitudinal factors referred to above. The future of the course seems by no means assured.

\section{Conclusion}

Given the preceding, we believe we have learned four key lessons about setting up and teaching a course in medical ethics to clinical students. First, if the course is to be successful, it must immediately strike students as relevant to what the practice of medicine both is and should be like. It should be geared to specific cases and designed to encourage maximum participation in discussion of those who attend. It should not, in short, take the form of simply a lecture or of a discussion dominated by professionals. Second, its success must be publicly evaluated by the students and any other medical staff who can be encouraged to attend. Without such assessment, even with a few keen supporters to begin with, it will be hard to convince those who believe that medical ethics cannot be taught but must be gleaned through a sort of moral osmosis of apprenticeship with the right sort of consultant. Such opponents will obviously be highly suspicious of outsiders (especially non-doctors!) purporting to fill this role. Third, it is crucial that everything about a new course be seen by both students and staff as 'formal' and on a par with other clinical work. One can always put together a course that will be reasonably successful for a - usually small - selfselected audience. The real trick is to reach those who fear the subject, for whatever reason, and who will look for an excuse not to attend and to minimise its importance. This is why graded compulsory assessment is so crucial. It is also why deans must insist that all consultants allow the students on their firms to attend scheduled ethics teaching and continue to do so in the face of opposition. We do not underestimate the difficulty of this given both the traditional structure of the clinical curriculum and the power of individual consultants in its operation. Thus, fourth and finally, for an ethics course to achieve longterm stability within a medical school it is not enough for it to be successful with students. It is crucial to forge alliances with as many people on the clinical staff as possible and certainly to meet with critics for discussion as soon as one hears of them.

All of the above takes time and can be as frustrating 
as it can be demanding. Yet the rewards are immense: all those involved agree that we have never experienced such exciting teaching with so much real gratitude and appreciation at the end of the day.

After graduating in Philosophy and Sociology at Georgia State University, Len Doyal BA MSc came to the UK as a Fulbright Fellow and gained an MSc in Logic and Scientific Method at the London School of Economics. $\mathrm{He}$ is Principal Lecturer in Philosophy at Middlesex Polytechnic where he teaches moral and political philosophy and politics of the natural and social sciences. He is also currently an Honorary Research Fellow in the Centre of Medical Law and Ethics at King's College, London.

Brian Hurwitz MRCP, MRCGP trained in medicine and the history and philosophy of science at Cambridge University. $\mathrm{He}$ is a general practitioner in Islington in North London and a Research Fellow at University College Hospital Medical School. Aside from medical ethics, his research interests include the primary care of patients with chronic disease.
Fohn $S$ Yudkin MD, MRCP trained in medicine at Cambridge University and at University College Medical School. He is a consultant physician in general medicine and diabetes at the Whittington Hospital in North London $\Rightarrow$ and is a Senior Lecturer in the Department of Medicine at University College, London, and at the Middlesex School of Medicine. He has published widely on clinical topics related to diabetes and on medicine, underdevelopment and the pharmaceutical industry. He and Brian Hurwitz are currently engaged in research on shared hospital and primary care for diabetics.

\section{Acknowledgement}

We would like to take this opportunity to thank Professor Ian Kennedy for the advice and encouragement he has given in all stages in the evolution of our course.

\section{References}

(1) This case is taken directly from Beauchamp $\mathrm{T}$ and Childress J. The principles of biomedical ethics. Oxford: Oxford University Press, 1983. 